\title{
Viscoelastic dynamic models of resilient elements used in railway tracks
}

\author{
Artur Zbiciak ${ }^{1, *}$, Cezary Kraśkiewicz ${ }^{1}$, Wojciech Oleksiewicz ${ }^{1}$, and Cezary Lipko ${ }^{2}$ \\ ${ }^{1}$ Warsaw University of Technology, Faculty of Civil Engineering, Institute of Roads and Bridges, \\ 16 Armii Ludowej Ave., 00-637 Warsaw, Poland \\ ${ }^{2}$ TINES Capital Group SA, TINES Railway, 23 Ciepłownicza St., 31-574 Cracow, Poland
}

\begin{abstract}
The paper presents selected theoretical aspects concerning viscoelastic dynamic modelling of resilient elements used in railway tracks. In order to characterize the research methodology for resilient mats in railway tracks, German Standards [1-4] are used herein. The main goal of the paper is to demonstrate the procedure of insertion loss calculation for a single degree of freedom truck system containing under-ballast mats. Selected results of certain dynamic characteristics of resilient truck systems (transmissibility, Bode and Nyquist plots etc.) are also discussed. The results of calculations visualized in graphs, were obtained by using own applications written in programming language MATLAB.
\end{abstract}

\section{Introduction}

Resilient mats are used for vibration isolation of railway track by reducing dynamic effects of rail traffic (vertical and transverse material vibration and structure-borne noise). Underballast mats are used in the track superstructure of bridges, track troughs and tunnels. They increase resilience between the ballast and the track, and reduce vibrations emitted into the environment.

In ballast-less track system resilient mats have similar purpose as under ballast mats. Nonetheless, a ballast-less track system is always an individual engineering solution for a particular application. In particular, in a slab track system resilient mats are applied horizontally and vertically directly below and from the sides of the concrete track base plate. The resulting floating slab track system is effective in mitigating vibrations, especially in low frequencies. It also can achieve a significant reduction in vibrations and structure-borne noise emissions at excitation frequencies above $\sqrt{2}$ times the tuning frequency [13-15].

Detailed description of various categories of resilient mats is given in our previous paper [12]. As it was emphasized in [12], there are no European standards, which would define the requirements, methodology of research and calculation for resilient mats in railway tracks. Thus, it is substantiated to use German Standards: DIN 45673-1 [1], DIN 45673-4 [2], DIN 45673-5 [3] and DIN 45673-7 [4]. Standard [4] covers parameters related

\footnotetext{
* Corresponding author: a.zbiciak@il.pw.edu.pl
} 
to the effectiveness of a track structure in mitigating vibrations and parameters needed for the static analysis and for the verification of track safety in floating slab track system. However, it is not possible to specify generally applicable load ranges for the resilient elements in a floating slab track as in case of under-ballast mats [3]. This is due to the fact that a floating slab track system is always an individual engineering solution for a particular application. Therefore, said standard sets out procedures for testing fitness for purpose, but does not contain requirements pertaining to the properties of resilient elements. All the substantial characteristics of resilient mats and procedures for their research are presented in studies [10-12].

In this paper we use mainly Standard [2] in order to demonstrate the procedure of insertion loss calculation for a single degree of freedom truck system containing underballast mats. Moreover, the results of certain dynamic characteristics of resilient truck systems (transmissibility, Bode and Nyquist plots etc.) are also discussed. Appropriate calculations were carried out by using own programs written in MATLAB.

\section{Mechanical model of resilient truck elements}

Rheological and kinetic properties of resilient truck elements can be characterized by linear viscoelastic dynamic models as it is proposed in Standards [1, 2]. The objective of this point is to provide a description of linear properties of an oscillatory system obeying the principle of superposition and presented in [1]. We will explain the terminology used in [1] pointing out some theoretical aspects being important for understanding the laboratory test procedures for resilient elements used in railway tracks [5-7, 9]. Moreover, this introductory part prepares basic nomenclature used in next chapter where detailed analytical calculations are carried out based on Standard [2].

Our analysis is focused on a viscoelastic single degree of freedom system containing one elastic element characterized by a spring coefficient $k[\mathrm{~N} / \mathrm{m}]$ and one viscous element with damping coefficient $d[\mathrm{Ns} / \mathrm{m}]$, linked in parallel. Moreover, effective mass of resilient elements is denoted by $m_{\text {eff }}[\mathrm{kg}]$. The system is excited by a force $F[\mathrm{~N}]$. The response of the system is specified by displacement $x[\mathrm{~m}]$. The equation of motion is as follows

$$
m_{\text {eff }} \ddot{x}(t)+d \dot{x}(t)+k x(t)=F(t)
$$

where a superimposed dot denotes differentiation with respect to time.

Harmonic excitation of the linear system and its steady-state response can be expressed via following equations

$$
\begin{gathered}
F(t)=F_{\mathrm{o}} \sin \omega t \\
x(t ; \omega)=x_{\mathrm{o}}(\omega) \sin (\omega t-\varsigma(\omega))
\end{gathered}
$$

where $\omega[\mathrm{rad} / \mathrm{s}]$ denotes angular frequency of excitation, $F_{\mathrm{o}}$ and $x_{\mathrm{o}}$ denote amplitudes of force and displacement respectively and $\varsigma$ is phase angle (loss angle). Angular frequency is related to ordinary frequency $f[\mathrm{~Hz}]$ by the relation $\omega=2 \pi f$.

The dynamic stiffness modulus of entire system can be defined as a ratio between amplitudes of excitation and response 


$$
k_{d y n}(\omega):=\frac{F_{\mathrm{o}}}{x_{\mathrm{o}}(\omega)}
$$

Analysing linear viscoelastic systems excited by harmonic functions allows application of complex variables. Let us assume the following transformation of variables

$$
\begin{aligned}
F(t) & =\operatorname{Im} F^{*}(t) \\
x(t ; \omega) & =\operatorname{Im} x^{*}(t ; \omega)
\end{aligned}
$$

The complex variables defined by Eqs. (4) are given as follows

$$
\begin{gathered}
F^{*}(t)=F_{\mathrm{o}} e^{i \omega t} \\
x^{*}(t ; \omega)=x_{\mathrm{o}}(\omega) e^{i \omega t-i \zeta(\omega)}
\end{gathered}
$$

where $i$ denotes imaginary unit.

Thus, it is possible to define the complex stiffness modulus containing both dynamic stiffness modulus as well as phase angle

$$
k^{*}(i \omega):=\frac{F^{*}(t)}{x^{*}(t ; \omega)}=k_{d y n}(\omega) e^{i \zeta(\omega)}
$$

where dynamic stiffness modulus constitutes an absolute value of the complex modulus

$$
k_{d y n}(\omega)=\left|k^{*}(i \omega)\right|
$$

Moreover, the complex stiffness modulus can be decomposed as follows

$$
k^{*}(i \omega)=k_{d y n}(\omega) \cos \varsigma(\omega)+i k_{d y n}(\omega) \sin \varsigma(\omega)=k^{\prime}(\omega)+i k^{\prime \prime}(\omega)
$$

where $k^{\prime}$ denotes the storage stiffness modulus representing elastic and kinetic properties of resilient track elements while $k^{\prime \prime}$ is the loss modulus used to represent viscous (damping) properties.

In case of linear viscoelastic systems, it is possible to define the loss factor being equal to the tangent of the loss angle. Thus, we obtain

$$
\eta(\omega)=\tan \varsigma(\omega)=\frac{k^{\prime \prime}}{k^{\prime}}
$$

Eventually, we can express the steady-state harmonic response of the system exited by sinusoidal force as follows

$$
x(t ; \omega)=F_{\mathrm{o}} \operatorname{Im}\left\{\frac{\exp (i \omega t)}{k^{*}(i \omega)}\right\}=F_{\mathrm{o}} U(\omega) \sin (\omega t-\varsigma(\omega))
$$

where $U(\omega)$ denotes dynamic compliance defined as an inverse of dynamic stiffness (see [1]). 
Consequently, $U(\omega)$ can also be interpreted as a magnitude of the complex compliance $U^{*}(i \omega)$ :

$$
U(\omega)=\left|U^{*}(i \omega)\right|=k_{d y n}^{-1}(\omega)
$$

Moving back to the analysis of viscoelastic dynamic system defined via Eq. (1), the complex stiffness modulus may be expressed by the following equation

$$
k^{*}(i \omega)=k-m_{e f f} \omega^{2}+i \omega d
$$

while the dynamic stiffness modulus and the loss factor are as follows

$$
\begin{gathered}
k_{d y n}(\omega)=\sqrt{\left(k-m_{\text {eff }} \omega^{2}\right)^{2}+(\omega d)^{2}} \\
\eta(\omega)=\frac{\omega d}{k-m_{\text {eff }} \omega^{2}}
\end{gathered}
$$

The above Eq. (12) can be substituted into Eq. (10) and Eq. (9) in order to obtain the solution of equation of motion (1), under sinusoidal force excitation (steady-state response) taking additionally $\varsigma(\omega)=\operatorname{atan} \eta(\omega)$.

As it was emphasized in [12] the Standard [1] introduces more precise definitions of the spring coefficient $k$ and dynamic stiffness modulus $k_{d y n}$. In case of the stiffness modulus, the following definitions are used in [1]: $k_{\text {stat }}$ - static stiffness under a quasi-static force, $k_{\text {stat } 0}-$ at-rest static stiffness, $k_{\text {kin }}-$ kinetic or lower-frequency stiffness under a harmonically varying force with frequencies up to $1 \mathrm{~Hz}$. Moreover, in case of the dynamic stiffness modulus, applied for the frequency range above $1 \mathrm{~Hz}$, the Standard [1] distinguishes between $k_{d y n 1}$ - lower-frequency dynamic stiffness and $k_{d y n 2}$ - higherfrequency dynamic stiffness.

\section{Insertion Loss and Transmissibility}

In case of resilient mats hysteretic damping model is used instead of viscous damping as it was presented in Eq. (1). The equation of motion in case of single degree of freedom system is as follows

$$
m_{e f f} \ddot{x}(t)+k(1+i \eta) x(t)=F(t)
$$

while the complex stiffness modulus is given by

$$
k^{*}(i \omega)=k(1+i \eta)-m_{\text {eff }} \omega^{2}
$$

In case of such formulation, the loss factor is a constant value not depending of frequency of excitation. For steady-state response it is possible to establish the following relationship between the loss factor $\eta$ and damping coefficient $d$ :

$$
d=\frac{\eta k}{\omega}
$$


Let us analyse two mechanical models shown in Fig. 1 representing rail track systems: reference (Fig. 1 - left picture) and vibro-isolated (Fig. 1 - right picture). Such a model is presented in Standard [2] for calculation of insertion loss.

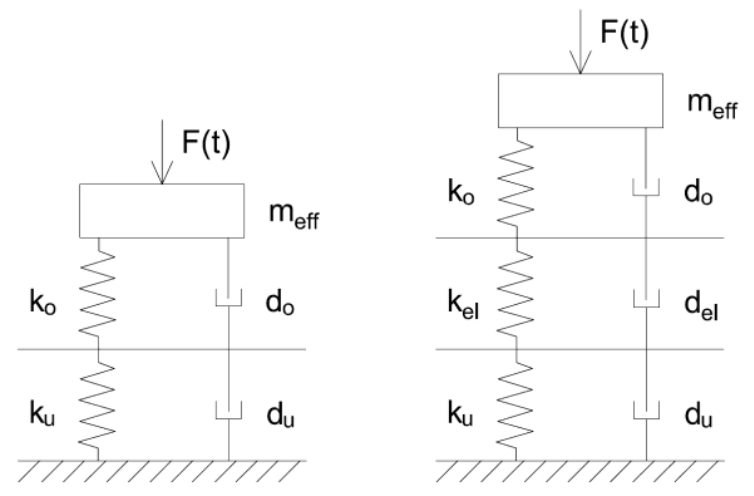

Fig. 1. Reference system (left picture) and system with Under-Ballast Mat (UBM) (right picture).

The reference system is composed of two layers. The parameters $k_{\mathrm{o}}=220 \mathrm{MN} / \mathrm{m}$ and $\eta_{\mathrm{o}}=0.35$ represent stiffness and damping of upper layer of the system (rail, fastening, sleeper and ballast) while $k_{u}=1500 \mathrm{MN} / \mathrm{m}$ and $d_{u}=1.2 \mathrm{MNs} / \mathrm{m}$ define lower layer (trackbed). In case of isolated system, an additional layer is considered representing under-ballast mat (UBM) and characterized by parameters $k_{e l}=140 \mathrm{MN} / \mathrm{m}$ and $\eta_{e l}=0.05$. Loss factors $\eta_{\mathrm{o}}$ and $\eta_{e l}$ can be replaced by equivalent damping coefficients $d_{\mathrm{o}}$ and $d_{e l}$ by applying Eq. (15).

Let us define the complex stiffness of entire reference system (lower and upper layer without mass)

$$
k_{r e f}^{*}(i \omega)=\left[\frac{1}{k_{\mathrm{o}}+i \omega d_{\mathrm{o}}}+\frac{1}{k_{u}+i \omega d_{u}}\right]^{-1}
$$

In case of isolated system the following relation holds

$$
k_{v i b}^{*}(i \omega)=\left[\frac{1}{k_{r e f}^{*}(i \omega)}+\frac{1}{k_{e l}+i \omega d_{e l}}\right]^{-1}
$$

Thus, it is possible to define complex transfer functions for both reference system $H_{r e f}^{*}(i \omega)$ as well as isolated system $H_{v i b}^{*}(i \omega)$ :

$$
\begin{aligned}
& H_{r e f}^{*}(i \omega)=\frac{k_{r e f}^{*}(i \omega)}{k_{r e f}^{*}(i \omega)-m_{e f f} \omega^{2}} \\
& H_{v i b}^{*}(i \omega)=\frac{k_{v i b}^{*}(i \omega)}{k_{v i b}^{*}(i \omega)-m_{e f f} \omega^{2}}
\end{aligned}
$$

Absolute value of the complex transfer function can be interpreted as transmissibility of harmonically excited system.

The above definitions can be used to establish so called insertion loss parameter 


$$
I L(\omega)=20 \cdot \log _{10}\left|\frac{H_{r e f}^{*}(i \omega)}{H_{v i b}^{*}(i \omega)}\right| \mathrm{dB}
$$

The results of calculation for both reference system and vibro-isolated system with UBM are visualized in Fig. 2 and 3. Horizontal axis used in Fig. 2 represents centre frequencies of $1 / 3$ octave bands. The plots depicted in Fig. 2 indicate a region of vibration effectiveness for approx. $f>33[\mathrm{~Hz}]$ where $I L>0 \mathrm{~dB}$.

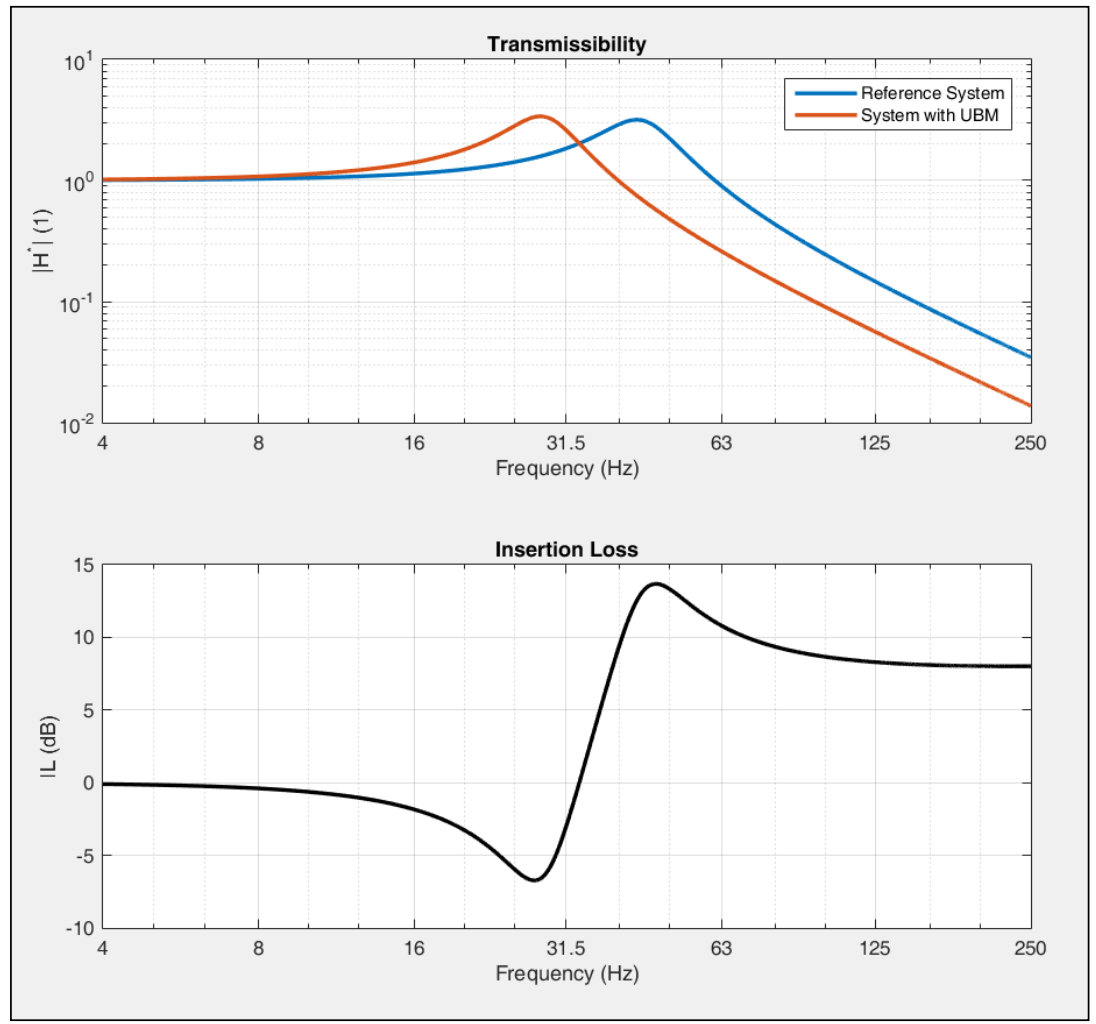

Fig. 2. Transmissibility and Insertion Loss - reference system and system with Under-Ballast Mat (UBM).

Moreover, one can define the complex compliance moduli od entire systems (reference and vibro-isolated) by the following equations

$$
\begin{aligned}
& U_{r e f}^{*}(i \omega)=\left[k_{r e f}^{*}(i \omega)-m_{e f f} \omega^{2}\right]^{-1} \\
& U_{v i b}^{*}(i \omega)=\left[k_{v i b}^{*}(i \omega)-m_{e f f} \omega^{2}\right]^{-1}
\end{aligned}
$$

Figure 3 visualizes dynamic characteristics of analysed systems based on complex compliance formulations. Bode diagrams represent magnitude and phase of the complex compliance as a function of frequency. Another plots to be shown in Fig. 3 are Nyquist graph ( $\operatorname{Im} U^{*}$ vs. $\operatorname{Re} U^{*}$ ) and Nichols graph (absolute value of $U^{*}$ as a function the phase angle). Analysing Nyquist graph leads to the conclusion that even for static excitation, when $\omega \rightarrow 0$, results in energy dissipation because the imaginary part of complex modulus 
does not equal to zero. The reason of such an effect is the application of hysteretic damping model of UBM.
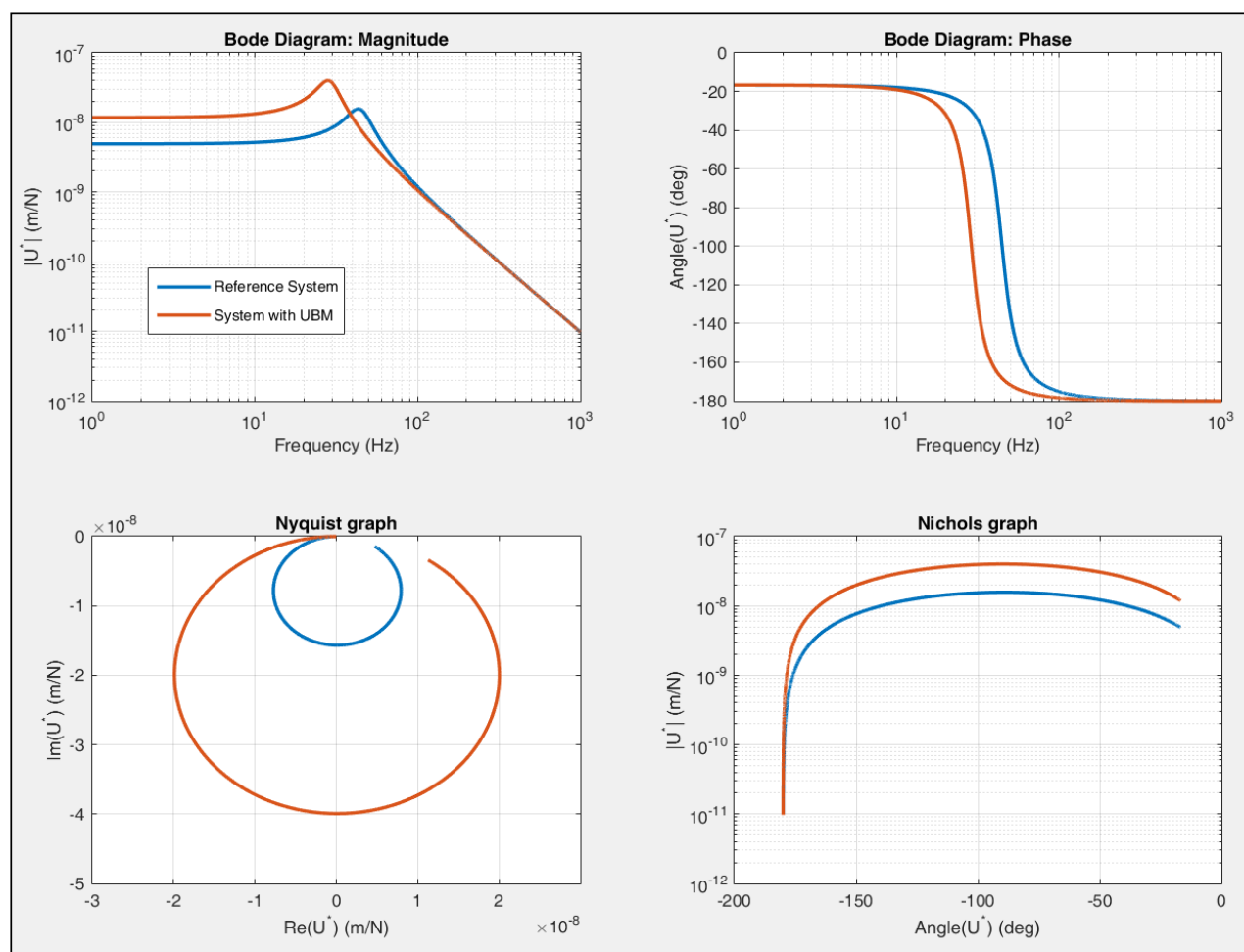

Fig. 3. Dynamic characteristics: Complex Compliance Modulus - reference rystem and rystem with Under-Ballast Mat (UBM)

\section{Conclusions}

Appropriate dynamic models of rail track system allow for calculation of various characteristics useful for evaluation of isolation effectiveness. The results of calculations presented in this paper were obtained by applying simple one degree of freedom system. It would be possible to use the same methodology in case of multi degree of freedom linear viscoelastic models representing rail track system with resilient elements. More general linear model should also contain non-classical viscoelastic elements described by fractional-order derivatives [8]. Such an approach would make possible to fit better experimental results.

Further explorations of problems related to the issue of modelling of resilient elements used in railway tracks by applying fractional rheological elements will be published in a subsequent paper.

\section{References}

1. DIN 45673-1:2010-08 Mechanical vibration. Resilient elements used in railway tracks. Part 1: Terms and definitions, classification, test procedures

2. DIN 45673-4:2008-07 Mechanical vibration. Resilient elements used in railway tracks. Part 4: Analytical evaluation of insertion loss of mounted track systems 
3. DIN 45673-5:2010-08 Mechanical vibration. Resilient elements used in railway tracks. Part 5: Laboratory test procedures for under-ballast mats

4. DIN 45673-7:2010-08 Mechanical vibration - Resilient elements used in railway tracks - Part 7: Laboratory test procedures for resilient elements of floating slab track systems

5. C. A. Brebbia et al., Lecture Notes in Engineering (Springer-Verlag, Berlin, 1985)

6. R. W. Clough, J. Penzien, Dynamics of Structures (McGraw-Hill, 1975)

7. W. Grzesikiewicz, J. Osiecki, J. Piotrowski, Fundamentals of rail vehicle dynamics (Publishing House of the Warsaw University of Technology, Warsaw, 1977)

8. W. Grzesikiewicz, A. Wakulicz, A. Zbiciak, International Journal of Mechanical Sciences 70, 90-98 (2013)

9. K. G. McConnell, P. S. Varoto, Vibration Testing: Theory and Practice, second ed. (John Wiley and Son, 2008)

10. C. Kraśkiewicz, C. Lipko, W. Oleksiewicz, A. Zbiciak, Materiały Konferencyjne, Stowarzyszenie Inżynierów i Techników Komunikacji Rzeczpospolitej Polskiej. Oddział w Krakowie 2(106), 89-113 (2015)

11. C. Kraśkiewicz, C. Lipko, W. Oleksiewicz, A. Zbiciak, Przegląd Komunikacyjny 9, 76-82 (2015)

12. C. Kraśkiewicz, C. Lipko, M. Płudowska, W. Oleksiewicz, A. Zbiciak, Procedia Engineering 153, 317-324 (2016)

13. R. G. Wettschureck, U. J. Kurze, ACUSTICA 58 pp. 177-182 (1985)

14. R. G. Wettschureck, U. J. Kurze, ACUSTICA 58 pp. 177-182 (1985)

15. R. G. Wettschureck, M. Heim, S. Mühlbachler, Proceedings Inter-noise 97, 577-580 (1997) 